\title{
Relationship between PD-L1 Expression and Tumor-Infiltrating Lymphocytes in Canine Mammary Tumor
}

\author{
Belarmino Eugênio Lopes-Neto ${ }^{1,2}$, Diana Célia Sousa Nunes-Pinheiro' ${ }^{1}$, Júlio Gil Vale Carvalheiraa, ${ }^{2,3}$ \\ Fernando Schmittt,5,6 \& Maria de Fátima Gärtner ${ }^{2,5,6}$
}

\begin{abstract}
Background: Studies pointed out that the tumor-infiltrating lymphocytes (TILs) have considerable importance in canine mammary tumor (CMT). On the other hand, cancer cells sometimes find ways to use immune checkpoint proteins as a shield to avoid being identified and attacked by the immune system as programmed death 1 ligand 1 (PD-L1). In this study, it was investigated the relationship between PD-L1 expression, stromal tumor-infiltrating lymphocytes (TILs) in canine mammary tumor (CMT), and the association with clinical and pathological characteristics of the tumors.

Materials, Methods \& Results: PD-L1 expression and TILs were assessed in 23 female dogs with CMT. The tumors were grouped into simple carcinoma $(C A, n=8)$ and complex carcinoma $(C C, n=15)$. Stromal TILs were assessed using two thresholds as TILs-Low representing $<50 \%$ of infiltrate within stromal area and TILs-High representing $\geq 50 \%$ of stromal area. Clinicopathological data of CMT was characterized according to key parameters, as well as survival rates. TILs evaluation within tumor stroma revealed that $65.2 \%(\mathrm{n}=15)$ of tumors had TILs-Low. PD-L1 expression and stromal TILs were significantly associated $(P=0.009)$. PD-L1 expression was observed in 39\% $(\mathrm{n}=9)$ of all tumors of which $17.4 \%(\mathrm{n}=4)$ were from CA group and 21.7\% $(n=5)$ were from CC group. PD-L1 expression within TILs was observed in 39\% $(n=$ 9 ) of the tumors. PD-L1 in malignant epithelium was present in all lymph node metastasis ( $n=5)$. PD-L1 was associated with involvement of regional lymph nodes $(P=0.034)$. Survival curves demonstrated TILs-Low had higher $(P=0.010)$ overall survival (OS) compared with TILs-High, and PD-L1+ and PD-L1- $(P=0.06)$ did not differed. The clinicopathological variables significantly correlated with OS by univariate analysis were the histological grade $(P=0.009)$, lymph node involvement $(P=0.004)$, stromal TILs $(P=0.016)$, and PD-L1+/TILs-High vs. PD-L1-/TILs-Low $(P=0.010)$. Multivariate analysis revealed that group of tumors with grade II-III was independent and negative prognostic factors for OS. Discussion: In this study, PD-L1 was differently expressed according to the histologic subtypes of TMC. Currently, has been showed the presence of PD-L1 in several canine cancer. Nevertheless, only a few studies have described PD-L1 protein expression in dog tumors and showed PD-L1 was constitutively expressed on canine tumor cell lines, although the levels of basal expression were very variable. This expression can be modulated by IFN- $\gamma$ exposure. In the present study, it was found a strong PD-L1 expression on TILs. The increase in PD-L1 cell surface expression by tumor cells can lead to decreased T-cell proliferation and increased apoptosis. In human breast cancer (BC) the PD-L1 expression was expressed in TILs and tumor epithelium. It has been reported the association of stromal TILs and PD-L1 expression with aggressive types and stages of BC. In this study, it was detected PD-L1 expression in malignant epithelium in all lymph node metastasis. PD-L1 overexpression was significantly associated with a series of clinicopathological parameters. It was demonstrated that PD-L1+/TILs-High had higher risk of overall survival (OS) than another group of interaction. High PDL1 expression may be a prognostic indicator for reduced OS, while tumor PD-L1+ was associated with poorer disease-free survival. The presence of TILs has shown to be potentially predictive and a prognostic factor in BC subtypes. In CMT, it has been reported that a high proportion of TILs was correlated to several malignancy characteristics. In relation to PDL1, further research is necessary to clarify this immune checkpoint as a potential therapeutic target and its application in clinical practice in CMT.
\end{abstract}

Keywords: breast cancer, canine mammary tumors, PD-L1, immune checkpoint, prognosis, overall survival.

DOI: $10.22456 / 1679-9216.102600$

Received: 18 July 2020

Accepted: 27 November 2020

Published: 11 January 2021

${ }^{1}$ Programa de Pós-Graduação em Ciências Veterinárias (PPGCV), Faculdade de Veterinária (FAVET), Universidade Estadual do Ceará (UECE), Fortaleza, CE, Brazil. ${ }^{2}$ Instituto de Ciências Biomédicas Abel Salazar (ICBAS); ${ }^{3}$ Centro de Investigação em Biodiversidade e Recursos Genéticos (CIBIO-InBIO); ${ }^{4}$ Faculdade de Medicina (FM); ${ }^{5}$ Instituto de Patologia e Imunologia Molecular da Universidade do Porto (IPATIMUP) \& ${ }^{6}$ Instituto de Investigação e Inovação em Saúde (i3S), Universidade do Porto (UP), Porto, Portugal. CORRESPONDENCE: B.E. Lopes Neto [belarminovet@ gmail.com.br]. Av. Dr. Silas Munguba n. 1700. Campus do Itaperi. CEP 60.714-903 Fortaleza, CE, Brazil. 


\section{INTRODUCTION}

Breast cancer $(\mathrm{BC})$ is the most frequently diagnosed malignancy among women [44]. Canine mammary tumors (CMT) are the major cancer in female dogs and malignant types can achieve $74 \%$ of tumors [42]. The involvement of the immune system in cancer has been widely studied and has presented paradoxical results in cancer control $[11,27,46]$. Several factors are involved in cancer progression, including tumor microenvironment components $[1,14]$.

Tumor-infiltrating lymphocytes (TILs) have considerable importance in CMT, having a positive relationship with features of malignancy, progression, prognosis, and survival of the dogs $[3,21,24]$. It has been show that cytotoxic $\mathrm{T}$ lymphocytes and natural killer cells participated in controlling and eliminating of tumor cells, while tumor-associated macrophages, B cells and regulatory $\mathrm{T}$ lymphocytes in tumor microenvironment were related to tolerance of neoplastic cell $[1,19,26,38]$.

Cancer cells sometimes find ways to use these immune checkpoint proteins as a shield to avoid being identified and attacked by immune cells. Recent studies have indicated that checkpoint molecules such as PD-L1 may play an important role in canine cancer mediated immune modulation [7,29]. PD-L1 is the ligand for the T cell inhibitory receptor PD-1 and is expressed on epithelial cells and various immune cells [20]. However, the interaction of stromal TILs and PD-L1 expression in CMT remains unclear. The aim of this study was to investigate the relationship of PD-L1 expression, stromal TILs in CMT, and the association with clinical and pathological characteristics of the tumors.

\section{MATERIALS AND METHODS}

Animals

Twenty-three female dogs with CMT admitted at the Veterinary Hospital of the Universidade Estadual do Ceará (UECE) between January and December 2016 were enrolled in the experiment. The animals were diagnosed by clinical and pathological evaluation. All the dogs' owners were informed about the study procedures and follow-up appointment, signing a free and informed consent form.

Animals with clinical or laboratory evidence of any other disease were not included in the present study, as well as those who had been previously treated for CMT. The search for distant metastasis was realized through chest radiographs and abdominal ultrasound. Sentinel lymph node was detected to search for regional metastasis. After surgery, tumor samples and lymph nodes were fixed in $10 \%$ buffered formalin and paraffin wax-embedded. The follow-up period lasted 365 days after surgery in each case and animal censured was that who had CMT as the cause of death. None of animals received anticancer therapy after surgery. The clinicopathological parameters evaluated in CMTbearing dogs were tumor size, ulceration, necrosis, vascular invasion, lymph nodes involvement, metastasis, clinical stage, histological grade, TILs intensity expression (Table 1).

Table 1. Clinicopathological Parameters of CMT.

\begin{tabular}{|c|c|c|}
\hline Parameter & \multicolumn{2}{|c|}{ CMT } \\
\hline $\begin{array}{l}\text { Histological Classification } \\
\mathrm{n}^{\circ}(\%)\end{array}$ & $\begin{array}{c}\text { CA } \\
8(35 \%)\end{array}$ & $\begin{array}{c}\mathrm{CC} \\
15(65 \%)\end{array}$ \\
\hline Age & $10.25( \pm 2.76)$ & $9.34( \pm 1.94)$ \\
\hline $\begin{array}{c}\text { Skin ulceration }(\%) \\
\text { No } \\
\text { Yes } \\
\end{array}$ & $\begin{array}{l}(5 \%) \\
(30 \%)\end{array}$ & $\begin{array}{l}(17 \%) \\
(48 \%)\end{array}$ \\
\hline $\begin{array}{c}\text { Tumor necrosis }(\%) \\
\text { No } \\
\text { Yes } \\
\end{array}$ & $\begin{array}{l}(5 \%) \\
(20 \%)\end{array}$ & $\begin{array}{l}(30 \%) \\
(45 \%)\end{array}$ \\
\hline $\begin{array}{c}\text { Vascular invasion }(\%) \\
\text { No } \\
\text { Yes }\end{array}$ & $\begin{array}{l}(20 \%) \\
(20 \%)\end{array}$ & $\begin{array}{c}(65 \%) \\
(0 \%)\end{array}$ \\
\hline $\mathrm{T}(\mathrm{cm})$ & $3.64( \pm 1.91)$ & $5.12( \pm 2.07)$ \\
\hline $\begin{array}{l}\mathrm{N}(\%) \\
\text { No } \\
\text { Yes }\end{array}$ & $\begin{array}{l}(20 \%) \\
(20 \%)\end{array}$ & $\begin{array}{c}(55 \%) \\
(5 \%)\end{array}$ \\
\hline $\begin{array}{l}\text { M (\%) } \\
\text { No } \\
\text { Yes } \\
\end{array}$ & $\begin{array}{l}(25 \%) \\
(10 \%)\end{array}$ & $\begin{array}{l}(65 \%) \\
(0 \%)\end{array}$ \\
\hline $\begin{array}{c}\text { TNM clinical stage (\%) } \\
\text { I } \\
\text { II } \\
\text { III } \\
\text { IV } \\
\text { V }\end{array}$ & $\begin{array}{c}(5 \%) \\
(12 \%) \\
(5 \%) \\
(5 \%) \\
(8 \%)\end{array}$ & $\begin{array}{c}(17 \%) \\
(12 \%) \\
(17 \%) \\
(19 \%) \\
(0 \%)\end{array}$ \\
\hline $\begin{array}{c}\text { Tumor grade }(\%) \\
\text { I } \\
\text { II } \\
\text { III }\end{array}$ & $\begin{array}{c}(12 \%) \\
(17 \%) \\
(6 \%)\end{array}$ & $\begin{array}{r}(40 \%) \\
(25 \%) \\
(0 \%)\end{array}$ \\
\hline
\end{tabular}

$\mathrm{T}$ : size of the primary tumor; $\mathrm{N}$ : involvement of regional lymph nodes; M: presence of distant metastases; CA: simple carcinoma; CC: complex carcinoma; $\mathrm{n}^{\circ}$ : numbers.

Sample selection and histological analysis

The tumor samples were stained with hematoxylin-eosin (H\&E) and sections $(3 \mu \mathrm{m})$ were classified according to the veterinary histological classification 
[13]. Two veterinary pathologists examined histologically a minimum of three sections of the mammary tumors, and after classification the tumors were grouped into simple carcinoma $(\mathrm{CA}, \mathrm{n}=8)$ which was composed of one type of malignant cell either resembling luminal epithelial or myoepithelial cells (Figure 1A). Tumors with foci of malignant-appearing cells or distinct nodules of such cells occurring in complex adenomas or benign mixed tumors (Figure 1B) were grouped as complex carcinoma $(\mathrm{CC}, \mathrm{n}=15)$.

Histological grade was assessed by classifying the carcinomas according to three different prognostic features such as tubular formation, nuclear pleomorphism, and mitotic counts [9,40]. Mitotic activity was assessed in 10 high-power fields (HPFs) in the most mitotically areas and considering one HPFs should be a field area of $2.37 \mathrm{~mm} 2$, in agreement with previous study [34]. Tumors were classified according to grading as grade I (well differentiated), grade II (moderately differentiated), and grade III (poorly differentiated). Lymph node samples were sectioned and included as following recommended criteria [8] and was used specific antibodies for cytokeratin AE1/AE3 performed to detect macro and micrometastasis (Figure 1I).

\section{Clinical staging}

The clinical stage classification consists of five stages (I to V) determined by the size of primary tumor (T), involvement of regional lymph nodes (N) and presence or absence of distant metastases (M) according modified criteria $[38,45]$. Tumor size was assessed by measuring the greater diameter of the largest malignant tumor present. The presence of lymph node involvement or distant metastasis was investigated as described above.

\section{Quantification of TILs}

Histopathological analyses of TILs were performed on $\mathrm{H} \& \mathrm{E}$-stained sections of twenty-three CMT from female dogs describes above. The analysis was conducted by two pathologists blinded to the clinical parameters (Nikon ECLIPSE E600 microscope) ${ }^{1}$. TILs were quantified as a percentage estimate of the stromal area adjacent to the tumor that contained lymphocytic and plasm cells infiltrate, using semi-quantitative evaluation as described in the literature [43]. Because heterogeneous histological features of CMT, the TILsassessment was done in different regions and reported the average. Thereby, two thresholds for TILs were reported as TILs-Low representing $<50 \%$ (Figure 1B) of infiltrate within stromal area and TILs-High representing $\geq 50 \%$ of analyses area (Figure $1 \mathrm{~A}$ ).

\section{Immunohistochemistry}

For immunohistochemistry staining, $3 \mu \mathrm{m} \mathrm{sec-}$ tions from paraffin wax-embedded TMC and lymph node were dewaxed and gradually hydrated through increasing concentrations of alcohol. Antigen unmasking was performed in citrate (PD-L1) or retrieval (AE1/ AE3) buffer by microwave heating for $10 \mathrm{~min}$. Endogenous peroxidase activity was blocked by incubating the section in methanol containing hydrogen peroxide (3\%) for $10 \mathrm{~min}$. Each section was blocked for $10 \mathrm{~min}$ at slide moisture chamber. A primary antibody incubation was performed overnight at $4^{\circ} \mathrm{C}$ using rabbit PDL1 monoclonal antibody $(1: 100 \text {; E1L3N })^{2}$, or mouse cytokeratin AE1/AE3 monoclonal antibody (1:300, MP-011-CM01 $)^{2}$ [25]. The sections were rinsed in TBS, incubated with post-primary at room temperature for $30 \mathrm{~min}$, and then a polymer incubation at room temperature for $30 \mathrm{~min}$. Finally, positive staining was visualized with 3-diaminobenzidine tetrahydrochloride (DAB). Sections were counterstained with Harris Hematoxylin solution. The sections were observed under an optical microscope. Human and dog placenta sections were used as positive controls to PD-L1 expression (Figure 1J), while human and canine stomach and bladder sections were used as negative control.

\section{PD-L1 evaluated}

The immunostaining was considered positive when $1 \%$ of tumor cells showed membranous as well as cytoplasmic staining since PD-L1 was expressed on the cell membrane and endomembrane system [37].

\section{Statistical analysis}

Statistical analyses were performed using SPSS version 24.0 (IBM) ${ }^{3}$. Pearson's $\chi^{2}$ tests were used to compare categorical variables and Mann-Whitney U test for quantitative variables. The relationship between clinicopathological characteristics and survival was examined using Kaplan-Meier log-rank survival analysis and univariate Cox proportional hazards regression to calculate hazard ratios (HR) for 95\% confidence intervals (95\% CIs). Variables statistically significant on univariate analysis were subsequently entered into a multivariate model using a backwards conditional method. $P \leq 0.05$ was considered significant. 


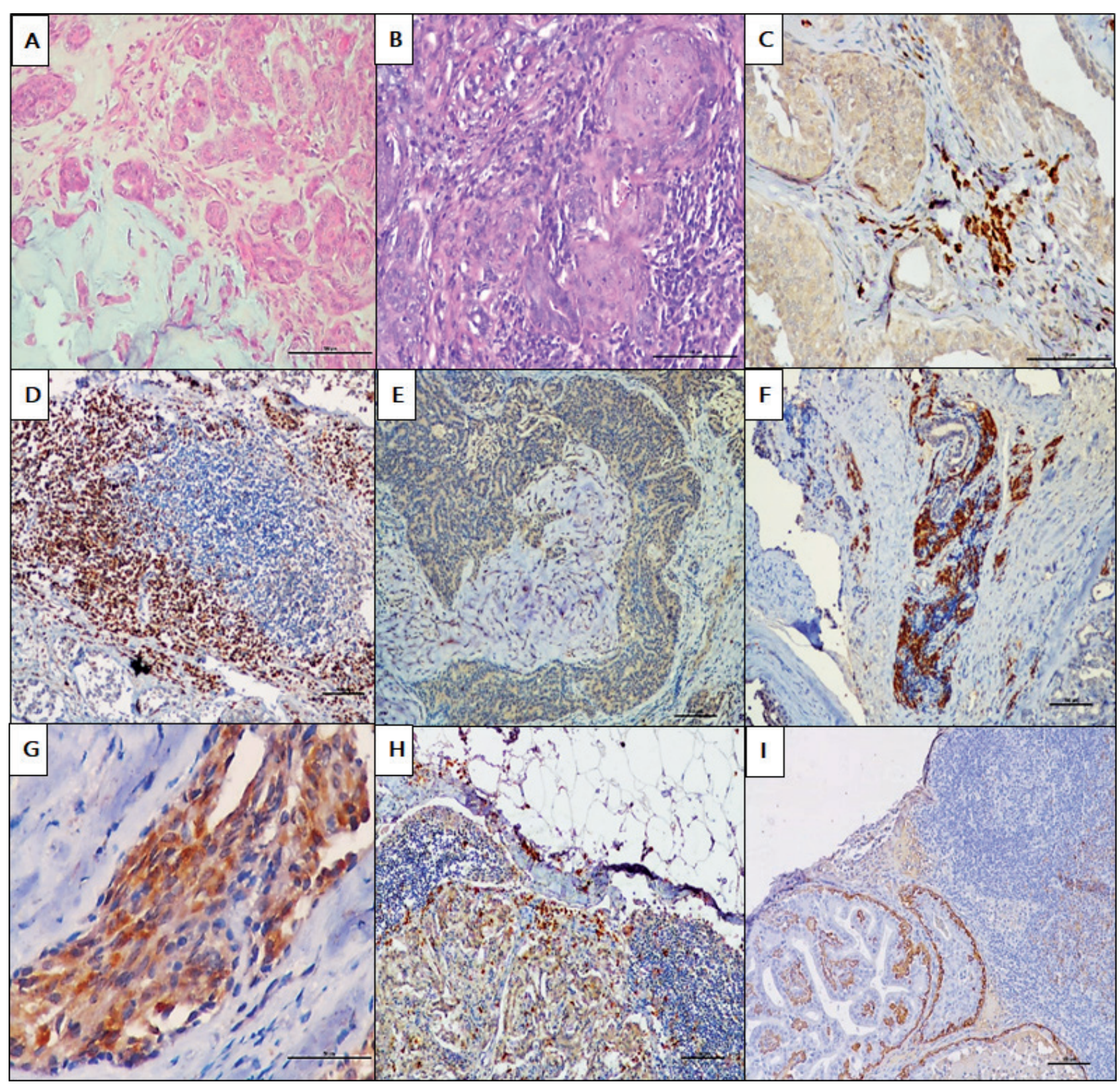

Figure 1. TILs assessment and PD-L1 expression within CMT and stromal TILs. A- Stromal TILs in solid carcinoma [H\&E; 200x]; B- Stromal TILs in benign mixed tumor [H\&E; 200x]; C- PD-L1 expression in complex carcinoma cellular infiltrate (200x); D- PD-L1 expression in tubular carcinoma cellular infiltrate (200x); E- Negative PD-L1 expression in complex carcinoma (100x); F- Positive PD-L1 expression in tubular carcinoma (100x); G- PD-L1 expression in malignant epithelium (400x); H- PD-L1 expression in lymph node metastasis (200x); I- AE1/AE3 expression in lymph node metastasis (100x).

\section{RESULTS}

\section{Clinicopathological characteristics}

This study includes 23 CMT-bearing dogs with clinical and pathological data summarized in Table 1. The mean age of CA and CC groups were $9.48 \pm 1.35$ and $9.89 \pm 2.87$ years old, respectively. Macroscopically, most of the tumors had a size between 3 and 5 $\mathrm{cm}$, and $78 \%(\mathrm{n}=18)$ had ulceration. Histopathologi- cal diagnoses were grouped as eight CA (1 tubular, 2 papillary, 3 tubular-papillary, 2 solids) and fifteen CC (9 complex carcinomas, 6 carcinomas in benign mixed tumors). Of all CMT, $52 \%(\mathrm{n}=12)$ of the cases had a histological grade I, $42 \%(\mathrm{n}=10)$ were grade II, and only $6 \%(n=1)$ were grade III. It was also observed that $65 \%(n=15)$ of the cases had areas of tumor necrosis. Vascular invasion was identified in $20 \%(\mathrm{n}=5)$ of all samples, $25 \%(\mathrm{n}=6)$ had lymph node metastasis, and 
in $10 \%(\mathrm{n}=2)$ was reported the presence of distant metastases.

\section{TILs assessment and associations}

Evaluation of the TILs within tumor stroma revealed that $65 \%(\mathrm{n}=15)$ of all samples had TILsLow (Figure 1 B). Most tumors showed stromal TILs distributed multifocal or diffuse inflammation. TILs assessment was reported according to percentage of stromal TILs. However, TILs did not have significant association between different clinicopathological parameter (Table 2).

\section{Expression of $P D-L 1$ and associations}

PD-L1 immunostaining was observed into cytoplasm and cytoplasmatic membrane of malignant epithelial cells (Figure $1 \mathrm{~F} \& \mathrm{G}$ ), and presented itself in $39 \%(n=9)$ of cases. The myoepithelial cells and metaplastic component were also evaluated in CC group and no PD-L1 expression was detected (Figure $1 \mathrm{C} \& \mathrm{E})$. PD-L1 expression was detected in malignant epithelium in all lymph node metastasis $(n=5)$, and only a few lymphocytes were immunostained (Figure $1 \mathrm{H})$. PD-L1 expression in stromal TILs (TILsPDL1) has shown immunostaining in $39 \%(n=9)$ of cases (Figure $1 \mathrm{C} \& D$ ). PD-L1 expression shown significant association with regional lymph nodes metastasis $(P$ $=0.034)$. PD-L1 expression and TILs (Figure 2A) were significantly associated between each other $(P$ $=0.009)$. In addition, PD-L1 ${ }^{+}$had higher $(P=0.033)$ percentage of stromal TILs then PD-L1 ${ }^{-}$(Figure $2 \mathrm{C}$ ).

\section{Survival analysis}

The survival analyses showed that $35 \%$ of animals died at the endpoint of follow-up. The median follow-up time was to 272 days (range, 40 to 365 days) for 14 dogs. Reasons for censorship included alive at the time of last follow-up (12 dogs), death due to other disease (two dogs). In addition, survival curves comparison stratified based on the TILs density demonstrated significant difference between TILs-Low and TILs-High (Figure $3 \mathrm{~A}$ ) in overall survival (OS). PD-L1- has high OS compared to PD-L1+ but did not significantly (Figure $3 \mathrm{~B}$ ).

The animals were divided into four subgroups: PD-L1+/TILs-High, PD-L1+/TILs-Low, PD-L1-/TILs High and PD-L1-/TILs-Low. In this way, Kaplan-Meier graphical analysis demonstrated that PD-L1-/TILs-Low had high OS compared PD-L1 ${ }^{+} /$TILs-High $(P=0.01)$ but did not show with other subgroups (Figure $3 \mathrm{C}$ ).
Clinicopathological variables significantly correlated with OS by univariate analysis using Cox proportional hazard model, the multivariate analysis revealed that group of tumors with grade II-III was independent and negative prognostic factors for OS (Table 3).

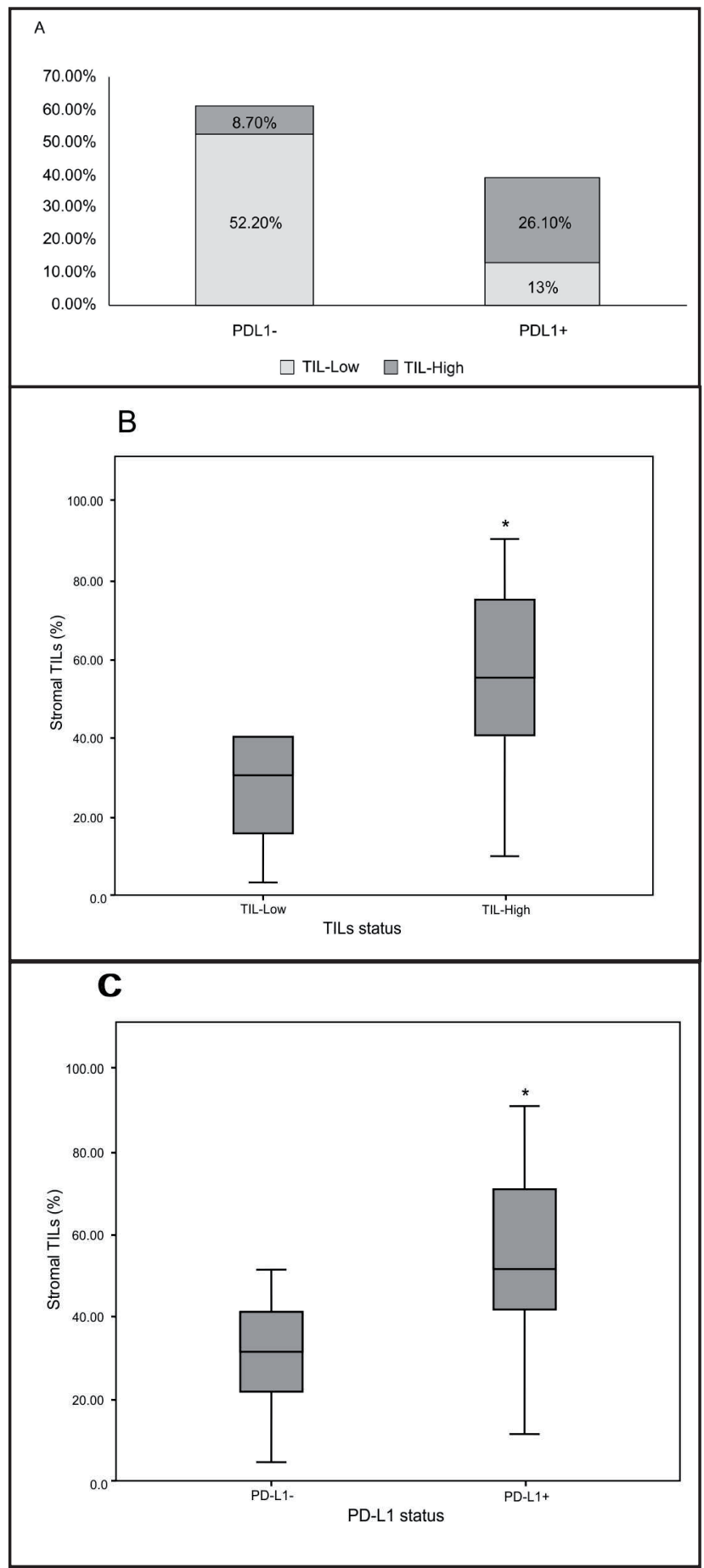

Figure 2. Relationship between PD-L1 expression and stromal TILs. A- Figures within this bar graph depict the percentage of cases with PDL1 expression and stromal TILs intensity. B- Analysis of TILs status and stromal TILs (\%). C-Analysis of PD-L1 expression status and stromal TILs (\%). *Significant differences at $P<0.05$. 


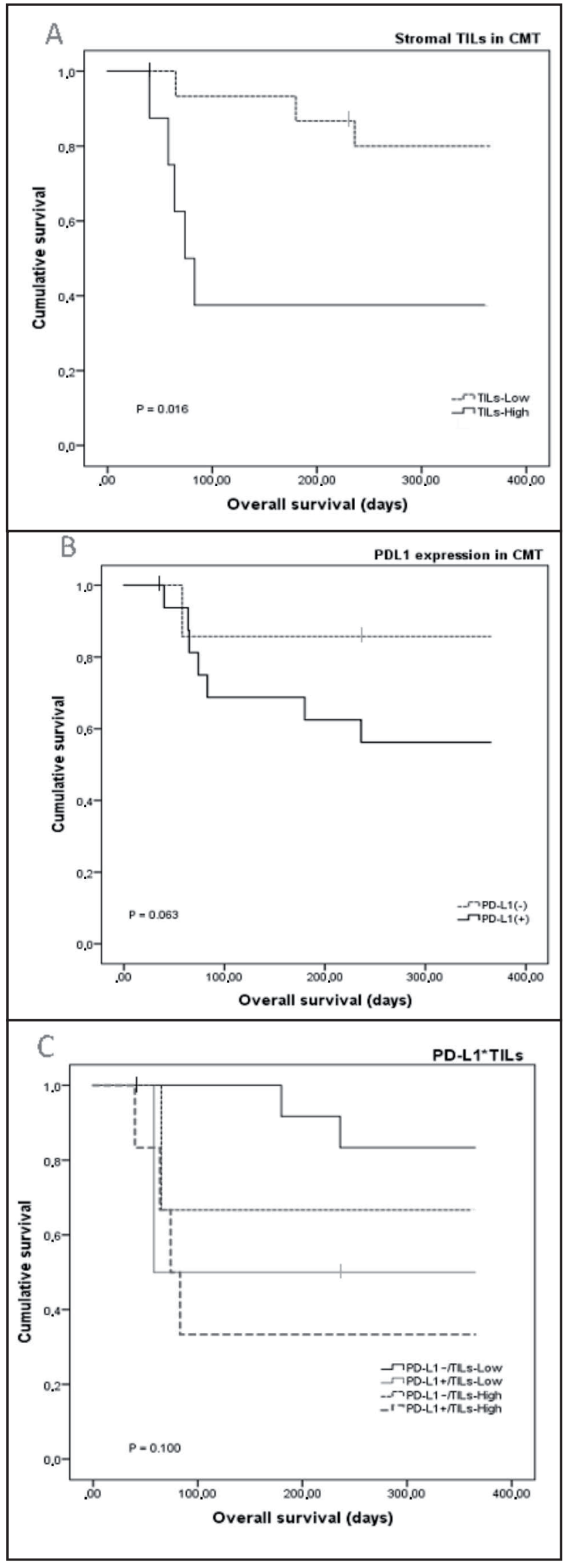

Figure 3. A- Overall survival for stromal TILs. B- PD-L1 expression. C- PD-L1* TILs.

\section{DISCUSSION}

PD-L1 expression has been demonstrated in a variety of solid tumor types in humans, including lung, melanoma, ovarian, colon, and $\mathrm{BC}[5,18,33]$. Currently, has been showed the presence of PD-L1 in several canine cancer, such as melanoma, mast cell tumor, renal cancer, and CMT [30]. In this study, we evaluated the clinical relevance of PD-L1 expression in CMT and the relationship with TILs. PD-L1 was differently expressed according to the histologic subtypes of TMC and TILs were associated with PD-L1 expression and showed poor prognosis when two parameters were correlated. Lymphocytes have role to suppress tumor growth, however, $\mathrm{T}$ cells activity may be regulated through binding of PD1 with PD-L1 in several types of cancer $[10,17,20]$. This marker has been studied as goal of antitumor immunotherapy [22].

The percentage of PD-1+CD4 $\mathrm{T}$ cells was significantly higher in dogs with cancer than in control dogs, whereas the increase of PD-1 expression by $\mathrm{CD} 8^{+} \mathrm{T}$ cells did not significant. In addition, the study showed that both $\mathrm{CD}^{+}$and $\mathrm{CD}^{+} \mathrm{T}$ cells, as well as neutrophils and monocytes, were negative for PD-L1 expression. However, a strong expression of PD-L1 was found on TILs, lymphocytes and plasm cells (Figure $1 \mathrm{C} \& D$ ). Few studies have been described PDL1 protein expression in dog tumors and showed that PD-L1 was constitutively expressed on canine tumor cell lines, although the levels of basal expression were very variable [32].

It has been described that the PD-1 expression in $\mathrm{CD}^{+}$and $\mathrm{CD}^{+} \mathrm{T}$ cells from canine peripheral blood in dogs with various types of cancer [7]. Different canine cancer cell lines showed upregulation of PD-L1 expression after IFN- $\gamma$ stimulation and by exposure to a TLR3 ligand. Similarly, canine macrophage did not express PD-L1 constitutively but was upregulated after IFN- $\gamma$ exposure [15]. In bovine lymphocytes, the PD-L1 expression was associated as inducing immunosuppression and lymphocyte cell death [16]. A promising antitumor activity was show using monoclonal antibodies against PD-L1 in oral malignant melanoma and undifferentiated sarcoma in dogs [31]. PD-1/PD-L1 were involved in the induction of T lymphocyte apoptosis and in regulating the production of nitric oxide, TNF- $\alpha$, and IL-4, as well as in reducing the parasitic load in dogs with leishmaniosis [6]. 
B.E. Lopes-Neto, D.C.S. Nunes-Pinheiro, J.G.V. Carvalheira, F. Schmitt \& M.F. Gärtner. 2021. Relationship between PD-L1 Expression and Tumor-Infiltrating Lymphocytes in Canine MammaryTumor.

Table 2. Association between PD-L1expression, stromal TILs and clinicopathological data of CMT.

\begin{tabular}{|c|c|c|c|c|c|c|}
\hline Clinicopathological parameter & PD-L1- $(\%)$ & $\mathrm{PD}-\mathrm{L} 1+(\%)$ & $P$-value & TILs-Low (\%) & TILs-High (\%) & $P$-value \\
\hline \multicolumn{7}{|l|}{ Histologic type } \\
\hline $\mathrm{CA}$ & $13.0 \%$ & $17.4 \%$ & 0.094 & $17.4 \%$ & $17.4 \%$ & 0.267 \\
\hline $\mathrm{CC}$ & $47.8 \%$ & $21.7 \%$ & & $47.8 \%$ & $17.4 \%$ & \\
\hline \multicolumn{7}{|l|}{ Grade of tumor } \\
\hline I & $17.4 \%$ & $4.3 \%$ & & $17.4 \%$ & $4.3 \%$ & \\
\hline II & $21.7 \%$ & $17.4 \%$ & 0.740 & $26.1 \%$ & $13.0 \%$ & 0.640 \\
\hline III & $21.7 \%$ & $17.4 \%$ & & $21.7 \%$ & $17.4 \%$ & \\
\hline \multicolumn{7}{|l|}{ Skin ulceration } \\
\hline Absent & $8.7 \%$ & $13 \%$ & 0.285 & $8.7 \%$ & $13.0 \%$ & 0.190 \\
\hline Present & $52.2 \%$ & $26.1 \%$ & & $56.5 \%$ & $21.7 \%$ & \\
\hline \multicolumn{7}{|l|}{ Tumor necrosis } \\
\hline Absent & $26.1 \%$ & $17.4 \%$ & 0.940 & $21.7 \%$ & $21.7 \%$ & 0.178 \\
\hline Present & $34.8 \%$ & $21.7 \%$ & & $43.5 \%$ & $13 \%$ & \\
\hline \multicolumn{7}{|l|}{$\mathrm{T}$} \\
\hline $\mathrm{T} 1<3 \mathrm{~cm}$ & $34.8 \%$ & $17.4 \%$ & & $34.8 \%$ & $17.4 \%$ & \\
\hline $\mathrm{T} 23-5 \mathrm{~cm}$ & $26.1 \%$ & $17.4 \%$ & 0.358 & $26.1 \%$ & $17.4 \%$ & 0.612 \\
\hline $\mathrm{T} 3>5 \mathrm{~cm}$ & $0 \%$ & $4.3 \%$ & & 0 & $4.3 \%$ & \\
\hline \multicolumn{7}{|l|}{$\mathrm{N}$} \\
\hline Negative & $56.5 \%$ & $21.7 \%$ & 0.034 & $56.5 \%$ & $21.7 \%$ & 0.190 \\
\hline Positive & $4.3 \%$ & $17.4 \%$ & & $8.7 \%$ & $13 \%$ & \\
\hline \multicolumn{7}{|l|}{ M } \\
\hline Negative & $56.5 \%$ & $34.8 \%$ & 0.744 & $60.9 \%$ & $30.4 \%$ & 0.644 \\
\hline Positive & $4.3 \%$ & $4.3 \%$ & & $4.3 \%$ & $4.3 \%$ & \\
\hline \multicolumn{7}{|l|}{ TNM clinical stage } \\
\hline I & $17.4 \%$ & $4.3 \%$ & & $17.4 \%$ & $4.3 \%$ & \\
\hline II & $21.7 \%$ & $13.0 \%$ & & $26.1 \%$ & $8.7 \%$ & \\
\hline III & $13.0 \%$ & $8.7 \%$ & 0.758 & $13 \%$ & $8.7 \%$ & 0.663 \\
\hline IV & $4.3 \%$ & $8.7 \%$ & & $4.3 \%$ & $8.7 \%$ & \\
\hline $\mathrm{V}$ & $4.3 \%$ & $4.3 \%$ & & $4.3 \%$ & $4.3 \%$ & \\
\hline \multicolumn{7}{|l|}{ TILs } \\
\hline TILs-Low & $52.2 \%$ & $13 \%$ & 0.009 & - & - & - \\
\hline TILs-High & $8.7 \%$ & $26.1 \%$ & & - & - & - \\
\hline
\end{tabular}

T: size of the primary tumor; $\mathrm{N}$ : involvement of regional lymph nodes; M: presence of distant metastases; $\mathrm{CA}$ : simple carcinoma; $\mathrm{CC}$ : complex carcinoma.

In this study, the relationship of PD-L1 expression and TILs has a strong association and TILs were immunostaining for anti-PD-L1.PD-L1 expression was described in $50 \%$ of $\mathrm{BC}$ was not restricted to the tumor epithelium, but was also expressed by TILs [12]. The increase in PD-L1 cell surface expression in tumor cells can lead to decreased T-cell proliferation and increased apoptosis [34]. However, it has been reported the association of stromal TILs and PD-L1 expression with aggressive types of $\mathrm{BC}$, and that both were already found in in situ stages [41].

It was found an association of lymph node metastasis with PD-L1 expression and high risk for
OS in animals with lymph node involvement. It can be supported by the presence of PD-L1 in malignant epithelium in all lymph node metastasis (Figure 1H). PD-L1 overexpression was associated with a series of clinicopathological parameters [23,37].

Along PD-L1 expression, decreased TILs were associated with a poor prognosis in triple-negative BC. Additionally, PD-L1+/TILs-Low was an independent negative prognostic factor for both recurrence-free survival and overall survival [36]. Interestingly, in contrast with the findings in $\mathrm{BC}$, it was demonstrated that PD-L1+/TILs-High had higher risk of OS than another 
Table 3. Univariate and multivariate cox proportional hazard model for overall survival.

\begin{tabular}{|c|c|c|c|c|c|c|c|c|}
\hline \multirow{3}{*}{ Variable } & \multicolumn{4}{|c|}{ Univariate } & \multicolumn{4}{|c|}{ Multivariate } \\
\hline & \multicolumn{4}{|c|}{$95 \% \mathrm{CI}$} & \multicolumn{4}{|c|}{$95 \% \mathrm{CI}$} \\
\hline & HR & Low & Upper & $P$-value & HR & Low & Upper & $P$-value \\
\hline \multicolumn{9}{|l|}{ Histologic type } \\
\hline Simple vs. Complex & 0.805 & 0.192 & 3.37 & 0.766 & & & & \\
\hline \multicolumn{9}{|l|}{ Grade of tumor } \\
\hline II-III vs. I & 9.87 & 1.20 & 65.58 & 0.009 & 14.77 & 1.15 & 88.36 & 0.038 \\
\hline \multicolumn{9}{|l|}{$\mathrm{T}(\mathrm{cm})$} \\
\hline$\geq 3 \mathrm{~cm}$ vs. $<3 \mathrm{~cm}$ & 2.03 & 0.25 & 16.55 & 0.495 & & & & \\
\hline \multicolumn{9}{|l|}{$\mathrm{N}$} \\
\hline pos vs neg & 6.33 & 1.50 & 23.69 & 0.004 & 1.22 & 1.19 & 7.794 & 0.833 \\
\hline \multicolumn{9}{|l|}{ M } \\
\hline pos vs neg & 1.46 & 0.18 & 11.99 & 0.719 & & & & \\
\hline \multicolumn{9}{|l|}{ TNM clinical stage } \\
\hline IV-V vs. I-III & 2.84 & 0.67 & 12.01 & 0.138 & & & & \\
\hline \multicolumn{9}{|l|}{ PD-L1 status } \\
\hline pos vs neg & 3.60 & 0.85 & 15.28 & 0.063 & & & & \\
\hline \multicolumn{9}{|l|}{$\mathrm{TILs}^{\mathrm{PDL} 1}$} \\
\hline pos vs neg & 1.43 & 0.28 & 7.12 & 0.658 & & & & \\
\hline \multicolumn{9}{|l|}{ Stromal TILs } \\
\hline TILs-high vs TILs-Low & 4.99 & 1.17 & 21.22 & 0.016 & 8.22 & 1.42 & 60.32 & 0.165 \\
\hline \multicolumn{9}{|l|}{ PD-L1*TILs } \\
\hline (PD-L1+/TILs-High vs. PD-L1+/TILs-Low) & 5.01 & 0.45 & 25.30 & 0.871 & & & & \\
\hline (PD-L1+/TILs-High vs. PD-L1-/TILs-High) & 2.46 & 0.22 & 27.30 & 0.420 & & & & \\
\hline (PD-L1+/TILs-High vs. PD-L1-/TILs-Low) & 6.67 & 1.98 & 37.14 & 0.010 & 2.026 & 0.180 & 22.78 & 0.567 \\
\hline
\end{tabular}

group of interaction. High PD-L1 expression may be a prognostic indicator for reduced OS, while PD-L1 ${ }^{+}$ expressed in tumor was associated with poorer diseasefree survival, although it was not significantly associated with OS [23].

In this work, the worst prognosis was associated to high stromal TILs in CMT, since TILs-High showed low OS $(P=0.01)$ compared with TILs-Low group. The presence of TILs has shown to be potentially predictive and a prognostic factor in human BC subtypes [2]. In canine mammary tumors, it has been reported that an high proportion of TILs was correlated to several malignancy characteristics $[24,28]$. In addition, when the $\mathrm{T}$ lymphocytes subpopulation were assessed in TILs of mammary tumors, the authors described an association of ratio $\mathrm{CD} 4^{+} / \mathrm{CD} 8^{+} \mathrm{T}$ cells with low survival rates, and a worst prognosis was associated with regulatory T lymphocytes [4].

\section{CONCLUSION}

Based on results it was concluded that exists an association between PD-L1 expression and stromal TILs from CMT, and its relation to a higher grade of tumor and lymph node involvement and supports the worst prognosis. On the other hand, the immunohistochemistry criteria for PD-L1 expression has not been standardized yet, however, this work showed good results using human PD-L1 antibody in dogs. Indeed, different thresholds for positivity PD-L1 expression has been used in the clinical trials and more studies are needed to achieve as a potential biomarker for CMT.

\section{MANUFACTURERS}

${ }^{1}$ Nikon Instruments Inc. Tokyo, Japan.

${ }^{2}$ Cell Signaling Technology Inc. Beverly, MA, USA.

${ }^{3}$ IBM Corp. Armonk, NY, USA.

Acknowledgements. The authors would like to thank the Department of Molecular Pathology and Immunology (ICBAS), University of Porto, for provided the antibodies for immunohistochemistry. 
Ethical approval. Experimental protocols were approved by the Ethics Committee for Use of Animals of the State University of Ceará, under number 8141226/2014. The dogs' owners in Brazil were informed about the study procedures and follow-up appointment, signing a free and informed consent form.
Declaration of interest. The authors declare no conflicts of interest. The authors alone are responsible for the content and writing of paper.

\section{REFERENCES}

1 Becht E., Giraldo N.A., Dieu-Nosjean M.C., Sautès-Fridman C. \& Fridman W.H. 2016. Cancer immune contexture and immunotherapy. Current Opinion in Immunology. 39: 7-13.

2 Bense R.D., Sotiriou C., Piccart-Gebhart M.J., Haanen J.B., van Vugt M.A., de Vries E.G., Schröder C.P. \& Fehrmann R.S.N. 2017. Relevance of tumor-infiltrating immune cell composition and functionality for disease outcome in breast cancer. Journal of the National Cancer Institute. 109: 1-9.

3 Carvalho M.I., Pires I., Prada J., Gregório H., Lobo L. \& Queiroga F.L. 2016. Intratumoral FoxP3 expression is associated with angiogenesis and prognosis in malignant canine mammary tumors. Veterinary Immunology and Immunopathology. 178: 1-9.

4 Carvalho M.I., Pires I., Prada J. \& Queiroga F.L. 2014. A role for T-lymphocytes in human breast cancer and in canine mammary tumors. BioMed Research International. 2014: 1-11.

5 Chen J., Jiang C.C., Jin L. \& Zhang X.D. 2016. Regulation of PD-L1: A novel role of pro-survival signalling in cancer. Annals of Oncology. 27: 409-416.

6 Chiku V.M., Silva K.L.O., Almeida B.F.M., Venturin G.L., Leal A.A.C., Martini C.C., Rezende E.F., Santos P.S. \& Lima V.M. 2016. PD-1 function in apoptosis of T lymphocytes in canine visceral leishmaniasis. Immunobiology. 221: 879-888.

7 Coy J., Caldwell A., Chow L., Guth A. \& Dow S. 2017. PD-1 expression by canine T cells and functional effects of PD-1 blockade. Veterinary Comparative Oncology. 15(4): 1487-1502.

8 de Araújo M.R., Campos L.C., Ferreira E. \& Cassali G.D. 2015. Quantitation of the regional lymph node metastatic burden and prognosis in malignant mammary tumors of dogs. Journal of Veterinary Internal Medicine. 29:1360-1367.

9 Elston C.W. \& Ellis I.O. 1991. Pathological prognostic factors in breast cancer. I. The value of histological grade in breast cancer: experience from a large study with long-term follow-up. Histopathology. 19: 403-410.

10 Emran A.A., Chatterjee A., Rodger E.J., Tiffen J.C., Gallagher S.J., Eccles M.R. \& Hersey P. 2019. Targeting DNA Methylation and EZH2 activity to overcome melanoma resistance to immunotherapy. Trends in Immunology. 40(4): 328-344.

11 Gama A., Paredes J., Gärtner F., Alves A. \& Schmitt F. 2008. Expression of E-cadherin, P-cadherin and beta-catenin in canine malignant mammary tumours in relation to clinicopathological parameters, proliferation and survival. The Veterinary Journal. 177: 45-53.

12 Garcia-Teijido P., Cabal M.L., Fernandez I.P. \& Perez Y.F. 2016. Tumor-infiltrating lymphocytes in triple negative breast cancer: The future of immune targeting. Clinical Medicine Insights Oncology. 10: 31-39.

13 Goldschmidt M., Peña L., Rasotto R. \& Zappulli V. 2011. Classification and grading of canine mammary tumors. Veterinary Pathology. 48: 117-131.

14 Hanahan D. \& Weinberg R.A. 2011. Hallmarks of cancer: the next generation. Cell. 144: 646-74.

15 Hartley G., Faulhaber E., Caldwell A., Coy J., Kurihara J., Guth A., Regan D. \& Dow S. 2017. Immune regulation of canine tumour and macrophage PD-L1 expression. Veterinary Comparative Oncology. 534-549.

16 Ikebuchi R., Konnai S., Okagawa T., Yokoyama K., Nakajima C., Suzuki Y., Murata S. \& Ohashi K. 2014. Influence of PD-L1 cross-linking on cell death in PD-L1-expressing cell lines and bovine lymphocytes. Immunology. 142: 551-561.

17 Ishii K., Shimizu M., Kogo H., Negishi Y., Tamura H., Morita R. \& Takahashi H. 2020. A combination of checkpoint blockade and $\alpha$-galactosylceramide elicits long-lasting suppressive effects on murine hepatoma cell growth in vivo. Immunobiology. 225: 151860.

18 Jelinic P., Ricca J., Oudenhove E.V., Olvera N., Merghoub T., Levine D.A. \& Zamarin D. 2018. Immune-active microenvironment in small cell carcinoma of the ovary, hypercalcemic type: rationale for immune checkpoint blockade. Journal of the National Cancer Institute. 110(7): 787-790. 
19 Jiang D., Gao Z., Cai Z., Wang M. \& He J. 2015. Clinicopathological and prognostic significance of FOXP3+ tumor infiltrating lymphocytes in patients with breast cancer: a meta-analysis. BMC Cancer. 5: 727.

20 Johnson D.B., Sullivan R.J. \& Menzies A.M. 2017. Immune checkpoint inhibitors in challenging populations. Cancer. 123: 1904-1911.

21 Karayannopoulou M., Anagnostou T., Margariti A., Kostakis C., Kritsepi-Konstantinou M., Psalla D. \& Savvas I. 2017. Evaluation of blood T-lymphocyte subpopulations involved in host cellular immunity in dogs with mammary cancer. Veterinay Immunology and Immunopathology. 186: 45-50.

22 Kennedy L.B. \& Salama A.K.S. 2020. A review of cancer immunotherapy toxicity. CA: A Cancer Journal for Clinicians. 70: 86-104.

23 Kim C, Kim EK, Jung H, Chon HJ, Han JW, Shin K-H, Shin K.H., Hu H., Kim K.S., Choi Y.D., Kim S., Lee Y.H., Suh J.S., Ahn J.B., Chung H.C., Noh S.H., Rha S.Y., Kim S.H. \& Kim H.S. 2016. Prognostic implications of PD-L1 expression in patients with soft tissue sarcoma. BMC Cancer.16: 434.

24 Kim J.-H., Chon S.-K., Im K.-S., Kim N.-H. \& Sur J.-H. 2013. Correlation of tumor-infiltrating lymphocytes to histopathological features and molecular phenotypes in canine mammary carcinoma : a morphologic and immunohistochemical morphometric study. Canadian Journal of Veterinary Research. 77: 142-149.

25 Kumaraguruparan R., Prathiba D. \& Nagini S. 2006. Of humans and canines: Immunohistochemical analysis of PCNA, Bcl-2, p53, cytokeratin and ER in mammarytumours. Research in Veterinay Science. 81: 218-224.

26 Law A.M.K., Lim E., Ormandy C.J. \& Gallego-Ortega D. 2017. The innate and adaptive infiltrating immune systems as targets for breast cancer immunotherapy. Endocrine-Related Cancer. 24: 123-144.

27 Liu D., Xiong H., Ellis A.E., Northrup N.C., Rodriguez C.O., O'Regan R.M., Dalton S. \& Zhao S. 2014. Molecular homology and difference between spontaneous canine mammary cancer and human breast cancer. Cancer Research. 74: 5045-5056.

28 Lopes Neto B.E., Souza S.C.B., Bouty L.M., Santos G.J.L, Oliveira E.S., Freitas J.C.C. \& Nunes Pinheiro D.C.S. 2017. CD4+, CD8+, FoxP3+ and HSP60+ expressions in cellular infiltrate of canine mammary carcinoma in mixed tumor. Acta Scientiae Veterinariae. 45: 1-8.

29 Maekawa N., Konnai S., Ikebuchi R., Okagawa T., Adachi M., Takagi S., Kagawa Y., Nakajima C., Suzuki Y., Murata S. \& Ohashi K. 2014. Expression of PD-L1 on canine tumor cells and enhancement of IFN- $\gamma$ production from tumor-infiltrating cells by PD-L1 blockade. PLoS One. 9: 1-14.

30 Maekawa N., Konnai S., Okagawa T., Nishimori A., Ikebuchi R., Izumi Y., Takagi S., Kagawa Y., Nakajima C., Suzuki Y., Kato Y., Murata S. \& Ohashi K. 2016. Immunohistochemical analysis of PD-L1 expression in canine malignant cancers and PD-1 expression on lymphocytes in canine oral melanoma. PLoS One. 11: 1-13.

31 Maekawa N., Konnai S., Takagi S., Kagawa Y., Okagawa T., Nishimori A., Ikebuchi R., Izumi Y., Deguchi T., Nakajima C., Kato Y., Yamamoto K., Uemura H., Suzuki Y., Murata S. \& Ohashi K. 2017. A canine chimeric monoclonal antibody targeting PD-L1 and its clinical efficacy in canine oral malignant melanoma or undifferentiated sarcoma. Science Reports. 7: 8951.

32 Maleki V. S, Garrigós C. \& Duran I. 2017. Biomarkers of response to PD-1/PD-L1 inhibition. Critical Review Oncology Hematology. 116: 116-124.

33 Marisa L., Svrcek M., Collura A., Becht E., Cervera P., Wanherdrick K., Buhard O., Goloudina A., Jonchère V., Selves J., Milano G., Guenot D., Cohen R., Colas C., Laurent-Puig P., Olschwang S., Lefèvre J.H., Parc Y., Ghiringhelli F., de Reynies A. \& Duval A. 2018. The balance between cytotoxic T-cell lymphocytes and immune checkpoint expression in the prognosis of colon tumors. Journal of the National Cancer Institute. 110(1): 68-77.

34 Meuten D.J., Moore F.M. \& George J.W. 2016. Mitotic count and the field of view area. Veterinary Pathology. 53: 7-9.

35 Mittendorf E.A., Philips A.V., Meric-Bernstam F., Qiao N., Wu Y., Harrington S., Su X., Wang Y., GonzalezAngulo A.M.,. Akcakanat A., Chawla A., Curran M., Hwu P., Sharma P., Litton J.K., Molldrem J.J. \& Alatrash G. 2014. PD-L1 Expression in triple-negative breast cancer. Cancer Immunology Research. 2: 361-370.

36 Mori H., Kubo M., Yamaguchi R., Nishimura R., Osako T., Arima N., Okumura Y., Okido M., Yamada M., Kai M., Kishimoto J., Oda Y. \& Nakamura M. 2017. The combination of PD-L1 expression and decreased tumor-infiltrating lymphocytes is associated with a poor prognosis in triple-negative breast cancer. Oncotarget. 8: 15584-1592.

37 Muenst S., Schaerli A.R., Gao F., Däster S., Trella E., Droeser R.A., Muraro M.G., Zajac P., Zanetti R., Gillanders W.E., Weber W.P. \& Soysal S.D. 2014. Expression of programmed death ligand 1 (PD-L1) is associated with poor prognosis in human breast cancer. Breast Cancer Research and Treatment. 146: 15-24. 
38 Okazaki T. \& Honjo T. 2006. The PD-1_PD-L pathway in immunological tolerance. Trends in Immunology. 27(4): 195-201.

39 Owen L. 1980. TNM Classification of tumours in domestic animals. Genebra: World Health Organization, pp.1-52.

40 Peña L., Gama A., Goldschmidt M.H., Abadie J., Benazzi C., Castagnaro M., Díez L., Gärtner F., Hellmén E., Kiupel M., Millán Y., Miller M.A., Nguyen F., Poli A., Sarli G., Zappulli V. \& de las Mulas J.M. 2014. Canine mammary tumors: a review and consensus of standard guidelines on epithelial and myoepithelial phenotype markers, HER2, and hormone receptor assessment using immunohistochemistry. Veterinay Pathology. 51: 127-145.

41 Polonia A., Pinto R., Cameselle-Teijeiro J.F., Schmitt F.C. \& Paredes J. 2017. Prognostic value of stromal tumour infiltrating lymphocytes and programmed cell death-ligand 1 expression in breast cancer. Journal of Clinical Pathology. 70: 860-867.

42 Rasotto R., Berlato D., Goldschmidt M.H. \& Zappulli V. 2017. Prognostic significance of canine mammary tumor histologic subtypes: an observational cohort study of 229 cases. Veterinary Pathology. 54: 571-578.

43 Salgado R., Denkert C., Demaria S., Sirtaine N., Pruneri G., Wienert S., Van den Eynden G., Baehner F.L., Penault-Llorca F., Perez E.A., Thompson E.A., Symmans W.F., Richardson A.L., Brock J., Criscitiello C., Bailey H., Ignatiadis M., Floris G., Sparano J., Kos Z., Nielsen T., Rimm D.L., Allison K.H., Reis-Filho J.S., Loibl S., Sotiriou C., Viale G., Badve S., Adams S., Willard-Gallo K. \& Loi S. - International TILs Working Group 2014. 2015. The evaluation of tumor-infiltrating lymphocytes (TILs) in breast cancer: recommendations by an International TILs Working Group 2014. Annals of Oncology. 26: 259-271.

44 Siegel R.L., Miller K.D. \& Jemal A. 2017. Cancer statistics, 2017. CA: A Cancer Journal of Clinicians. 67: 7-30.

45 Sorenmo K.U., Rasotto R., Zappulli V. \& Goldschmidt M.H. 2011. Development, anatomy, histology, lymphatic drainage, clinical features, and cell differentiation markers of canine mammary gland neoplasms. Veterinary Pathology. 48: 85-97.

46 Timmermans-Sprang E.P.M., Gracanin A. \& Mol J.A. 2017. Molecular signaling of progesterone, growth hormone, Wnt, and HER in mammary glands of dogs, rodents, and humans: new treatment target identification. Frontier in Veterinary Science. 4: 1-13. 